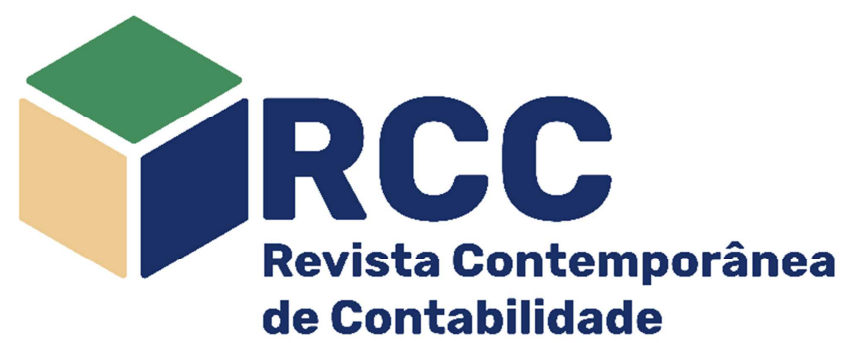

\title{
Potenciais modelos de negócios disruptivos no mercado contábil: estudo de caso com empresas brasileiras
}

\author{
Potential disruptive business models in the accounting market: case study with Brazilian companies
Potenciales modelos de negocios disruptivos en el mercado contable: estudio de caso con empresas brasileñas

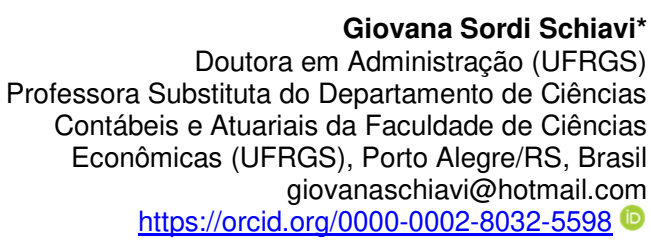

Doutora em Administração (UFRGS) essora Substituta do Departamento de Ciências Contábeis e Atuariais da Faculdade de Ciências giovanaschiavi@hotmail.com https://orcid.org/0000-0002-8032-5598 (i)

\author{
Ariel Behr \\ Doutor em Administração (UFRGS) \\ Professor Adjunto do Departamento de \\ Ciências Contábeis e Atuariais da Faculdade de Ciências \\ Econômicas (UFRGS), Porto Alegre/RS, Brasil \\ ariel.behr@ufrgs.br \\ https://orcid.org/0000-0002-9709-0852 (1)
}

Gwendole Ramos Duarte Mestre em Administração (UFRGS), Porto Alegre/RS, Brasil gwen.duarte@gmail.com https://orcid.org/0000-0001-8311-6751

Endereço do contato principal para correspondência* Avenida João Pessoa, 52, Bairro Centro Histórico, CEP: 90040- 000 - Porto Alegre/RS, Brasil

\section{Resumo}

Visando a sustentabilidade e competitividade no mercado, empresas contábeis buscam compreender as transformações geradas pelas novas tecnologias digitais, que estão impactando a profissão contábil e inovando diferentes elementos dos negócios. Nesse contexto, o presente estudo tem como objetivo descrever as características de potenciais modelos de negócios disruptivos existentes no mercado contábil brasileiro, por meio de um estudo de caso único e integrado com seis empresas inovadoras atuantes em diferentes áreas da contabilidade. Apesar da emersão de novos modelos de negócios serem um alerta para as mudanças no cenário contábil empresarial, os resultados evidenciaram que os modelos tradicionais ainda estão sendo pouco perturbados pelos modelos inovadores, em especial por se concentrarem em uma fatia específica do mercado, não explorada costumeiramente pelos modelos tradicionais. Os resultados evidenciaram a influência de novos recursos tecnológicos apoiando atividades e processos contábeis; e o conhecimento contábil como recurso essencial para ambos os modelos de negócio.

Palavras-chave: Modelos de negócios; Modelos de negócios disruptivos; Tecnologia digital; Inovação; Contabilidade

\begin{abstract}
Aiming at sustainability and competitiveness in the market, accounting companies seek to understand the transformations generated by new digital technologies, which are impacting the accounting profession and innovating different elements of the business. In this context, this study aims to describe the characteristics of potential disruptive business models in the Brazilian accounting market, through a single and integrated case study with six innovative companies operating in different areas of accounting. Although the emergence of new business models is an alert to changes in the business accounting scenario, the results showed that traditional models are still little disturbed by innovative models, especially as they focus on a specific slice of the market, not usually explored by traditional models. The results showed the influence of new technological resources as a support of the accounting activities and processes; and accounting knowledge as an essential resource for both business models.
\end{abstract}

Keywords: Business models; Disruptive business models; Digital technology; Innovation; Accounting

\section{Resumen}

Con el objetivo de la sostenibilidad y la competitividad en el mercado, las empresas contables buscan 
comprender las transformaciones que generan las nuevas tecnologías digitales, que están impactando la profesión contable e innovando diferentes elementos del negocio. En este contexto, este estudio tiene como objetivo describir las características de los modelos de negocio potencialmente disruptivos en el mercado contable brasileño, a través de un estudio de caso único e integrado con seis empresas innovadoras que operan en diferentes áreas de la contabilidad. Aunque la aparición de nuevos modelos de negocio es una alerta a los cambios en el escenario de la contabilidad empresarial, los resultados mostraron que los modelos tradicionales todavía se ven poco afectados por los modelos innovadores, especialmente porque se centran en un segmento específico del mercado, que no se suele explorar. modelos tradicionales. Los resultados mostraron la influencia de nuevos recursos tecnológicos que apoyan las actividades y los procesos contables; y el conocimiento contable como recurso fundamental para ambos modelos de negocio. Palabras clave: Modelos de negocios; Modelos de negocios disruptivos; Tecnología; Innovación; Contabilidad

\section{Introdução}

Para auxiliar no processamento dos dados e na divulgação das informações, o profissional contábil incluiu diferentes recursos tecnológicos em sua rotina de trabalho ao longo do tempo (Gelinas \& Gogan, 2006). Desde os primeiros sistemas informacionais computadorizados, até os softwares contábeis, os sistemas integrados de gestão empresarial (ERP) e o advento da internet, todos esses recursos revelam alterações significativas no funcionamento dos processos contábeis (Knudsen, 2020). Atualmente, as novas tecnologias digitais são as responsáveis por mudanças significativas em diferentes segmentos, inclusive na Contabilidade (Remane, Hanelt, Nickerson, \& Kolbe, 2017). O uso de softwares de armazenamento e análise de dados, de soluções em nuvem, de plataformas digitais e de sistemas para gerenciamento de documentos são exemplos de tecnologias digitais que permitem maior flexibilidade nas ações dos contadores (Bygren, 2016; Sebastian et al., 2017; Knudsen, 2020).

Entretanto, mais desafiante que a incorporação de novas soluções tecnológicas nos processos contábeis é a maneira pela qual essas tecnologias modificam os fundamentos dos tradicionais modelos de negócios (Dimitriu \& Matei, 2015). Além do suporte às atividades, essas soluções possuem potencial de mudança nos negócios (Bygren, 2016; Remane et al., 2017). Frey e Osborne (2017) destacam que a compreensão da mudança tecnológica e sua influência sobre os negócios é fundamental para garantir a sobrevivência e sustentabilidade das empresas contábeis. $O$ atual cenário aponta que diferentes elementos de negócios estão sendo alterados para se aproveitar as oportunidades que surgem com as novas soluções digitais (Remane et al., 2017).

Dimitriu e Matei (2015) revelam, por exemplo, que as soluções digitais modificam, principalmente, as atividades; e a agilidade no acesso às informações permite que outros elementos sejam alterados, como os aspectos financeiros. Para Basova (2017), a eficiência adquirida pelo uso de novos recursos tecnológicos tem potencial para contribuir com a proposição de valor, ao oferecer para os clientes soluções de análise de dados. Esses aspectos destacam a importância de se compreender as estruturas dos modelos de negócios em contextos de alterações tecnológicas (Metallo, Agrifoglio, Schiavone, \& Mueller, 2018). Isso porque os modelos de negócios são ferramentas que auxiliam a criar ou modificar estruturas de negócios, sendo o Canvas um modelo que sistematiza aspectos estratégicos, operacionais e financeiros, e que permite ajustes para acompanhar as tendências do mercado (Osterwalder \& Pigneur, 2011).

A preocupação na organização dos elementos empresariais tem despertado o interesse de gestores para a inovação dos modelos de negócios (Schiavi, Behr, \& Marcolin, 2019). Nesse sentido, os modelos de negócios disruptivos surgem para substituir os modelos existentes, adequando as estruturas organizacionais às novas tecnologias e possibilitando a oferta de produtos ou serviços de valor único ao mercado (Mitchell \& Coles, 2004; Markides, 2006; Hwang \& Christensen, 2008; Wu, Ma, \& Shi, 2010). No contexto das empresas contábeis, a própria natureza dos negócios está se alterando em função das novas soluções tecnológicas. A automatização e a digitalização das atividades não só trazem eficiência para o cumprimento das obrigações contábeis (Knudsen, 2020), como criam oportunidades de fornecer serviços de alto valor agregado (Baron, 2016; Basova, 2017).

Diante desse contexto, este artigo tem por objetivo descrever as características de potenciais modelos de negócios disruptivos existentes, atualmente, no mercado contábil brasileiro. Realizou-se um estudo de caso único e integrado, com empresas atuantes em diferentes áreas da Contabilidade, as quais vem buscando inovações para seus negócios. Na etapa de coleta dos dados, foram realizadas entrevistas com os gestores e coletados documentos institucionais dessas empresas. Complementarmente, foram feitas entrevistas com profissionais acadêmicos e de mercado, que auxiliaram a caracterizar os tradicionais modelos de negócios da área contábil, possibilitando uma comparação com os novos modelos que surgem diante da entrada de novas tecnologias.

Chiu, Liu, Muehlmann e Baldwin (2019) destacam que as mudanças proporcionadas pelas tecnologias digitais no campo contábil merecem a atenção de pesquisadores e gestores. Investigar esse cenário emergente é necessário, em razão das mudanças no mercado contábil pelas inovações que surgem 
com as novas tecnologias, as quais causam impactos na forma como os profissionais e os negócios dessa área atuam (Guthrie \& Parker, 2016). Esta pesquisa fornece um melhor entendimento sobre o atual comportamento do mercado contábil brasileiro. Ao apresentar tendências de novos modelos de negócios e ao compará-los com os tradicionais modelos existentes, o presente artigo traz contribuições para o campo e para os gestores sobre a forma de gerenciamento do impacto tecnológico nos negócios e as possibilidades de inovação na prática dos negócios contábeis.

\section{Disrupção nos Modelos de Negócios Contábeis}

Os estudos iniciais sobre as disrupções no mercado concentraram-se nas tecnologias e inovações descontínuas, os quais apontavam o declínio de grandes empresas ao ignorarem o potencial de novas tecnologias que, inicialmente, não atendiam às necessidades de clientes convencionais (Bower \& Christensen, 1995). Essas análises foram estendidas até o conceito de modelos de negócios disruptivos, unindo os aspectos gerencias dos modelos de negócios com as rupturas tecnológicas no papel das tecnologias disruptivas (Christensen \& Raynor, 2003). Isso porque a disrupção dos modelos de negócios é percebida quando as tecnologias emergentes e inovações tornam-se críticas em modelos de negócios que não estão preparados para essas mudanças (Moore, 2004). A comercialização de uma nova tecnologia ou de uma inovação exige das empresas a compreensão de seus modelos de negócio, principalmente quando as oportunidades apresentadas pelas mesmas não se encaixam nos modelos de negócios existentes (Chesbrough \& Rosenbloom, 2002). Assim, os modelos de negócios disruptivos surgem para substituir os modelos de negócios existentes, seja pela reorganização ou pela criação de estruturas organizacionais, visando adequar o modelo de negócio às novas tecnologias ou à inovação (Mitchell \& Coles, 2004; Hwang \& Christensen, 2008; Wu et al., 2010).

As disrupções nos modelos de negócios não atuam, necessariamente, na descoberta de novos produtos ou serviços, podendo agir na redefinição de produtos e serviços existentes e na forma de fornecimento aos clientes (Markides, 2006). Schiavi et al. (2019) destacam, por exemplo, o impacto de tecnologias e inovações disruptivas em questões estruturais dos modelos de negócios (readequação ou criação de novas estruturas de negócios que acompanham os potenciais de tecnologias emergente no processamento ou no fornecimento de novos serviços e produtos). Por isso, para se criar, entregar e capturar valor, o modelo de negócio articula diferentes atividades e elementos empresariais. Baden-Fuller e Morgan (2010) apontam que um modelo de negócio é constituído por diversos componentes estratégicos, devendo ser dada atenção na forma como esses componentes são organizados. Um dos modelos de negócios mais difundidos surgiu a partir da síntese de diferentes elementos organizacionais. O modelo Canvas, apresentado por Osterwalder e Pigneur (2011), destaca nove elementos, voltados a questões estratégicas, operacionais e financeiras, e suas interligações (Tabela 1).

Tabela 1:

Modelo de negócio Canvas

Componentes

Descrição

Proposta de valor

Segmento de clientes

Relacionamento com clientes

Canais

Busca resolver os problemas dos clientes e satisfazer suas necessidades, com propostas de valor.

Uma organização serve a um ou diversos segmentos de clientes.

O relacionamento com clientes é estabelecido e mantido com cada segmento de clientes.

Atividades-chave

As propostas de valor são levadas aos clientes por canais de comunicação, distribuição e vendas.

Recursos principais

Conjunto de processos (atividades-chave) executados para oferecer e entregar os elementos previamente descritos.

Parcerias principais

Estrutura de custos

Fontes de receita

Os recursos principais são os elementos para oferecer e entregar os elementos previamente descritos.

Algumas atividades são terceirizadas e alguns recursos são adquiridos fora da empresa.

Os elementos do modelo de negócios resultam na estrutura de custos.

Nota. Adaptado de "Business model generation - Inovação em modelos de negócios" de A. Osterwalder, A., \& Y. Pigneur, 2011.

O cenário interativo do Canvas proporciona uma ferramenta que auxilia o empresário a criar ou a modificar seu modelo de negócio, sendo importante sua aplicação no processo de inovação dos modelos de negócios (Osterwalder \& Pigneur, 2011). O pioneirismo de Schumpeter (1934) sobre a análise econômica do conceito de inovação revela que o processo de inovação é fundamental para a geração de vantagem competitiva, para o desenvolvimento econômico e para as mudanças de mercado e da sociedade. Schumpeter (1934) também ressalta que a inovação e o progresso tecnológico são a base para o dinamismo da economia. Esses aspectos estão ainda mais evidentes no cenário econômico atual. Indústrias e carreiras estão sendo interrompidas e transformadas pela entrada de novas tecnologias (Knudsen, 2020). Novos modelos de negócios estão surgindo e alterando os mercados, por meio de novas formas de entregas de valor. E a obtenção de vantagem competitiva está cada vez mais pautada no atendimento das necessidades dos clientes. 
Diante desse contexto, diferentes áreas, inclusive as mais tradicionais, enfrentam um dos períodos mais desafiadores do mercado (Guthrie \& Parker, 2016). O setor contábil é um exemplo que tem presenciado perturbações em função das novas tecnologias que alteram suas atividades (Pan \& Seow, 2016). E esse cenário tende a se ampliar no futuro, uma vez que a área contábil foi identificada como um negócio no qual a digitalização deverá crescer ainda mais nos próximos anos (Knudsen, 2020). Ainda, as necessidades e o comportamento dos clientes dos serviços contábeis também estão em transformação. Mudanças estratégicas nas estruturas empresariais e nas atividades contábeis são necessárias para melhorar a experiência desse cliente, seja pela eficiência na execução das funções contábeis, por uma melhor forma de comunicação ou por uma entrega de alto valor agregado (Baron, 2016; Bygren, 2016).

Os modelos de negócios contábeis estão em um processo de mudança significativa na forma como se cria, se entrega e se captura valor, e algumas tendências já podem ser verificadas no mercado. Conforme o relatório da Crunshbase sobre o impacto disruptivo na Contabilidade, as tarefas de rotina executadas nos escritórios contábeis, como entrada de dados e escrituração, são processos cada vez mais vulneráveis à digitalização e à automação (Cokins \& Angel, 2017). O mesmo relatório destaca a relevância das tecnologias para a auditoria, através do uso de inteligência artificial para trabalhar grandes quantidades de dados, possibilitando chegar em amostras mais relevantes e aumentando a velocidade na execução dessas atividades. Outra tendência que vem marcando o cenário contábil é o uso de tecnologias para fornecer insights, através de intensivas análises de dados (Pan \& Seow, 2016; Ransbotham \& Kiron, 2017), que geram vantagem competitiva e satisfação para o cliente (Baron, 2016). Tais aspectos salientam a figura do "contador-consultor" na era digital, permitindo ao profissional contábil agregar mais valor aos negócios de seus clientes (Baron, 2016). No atual cenário, a capacidade do contador em obter vantagem competitiva depende da combinação de habilidades voltadas ao conhecimento técnico e prático, ao pensamento empresarial crítico, à visão estratégica e ao gerenciamento de relacionamento (Chartered Accountants, 2015).

Nesse sentido, ao apresentar uma análise de mudanças que vêm ocorrendo por causa das novas tecnologias presentes no mercado contábil, um dos pontos de destaque de Almeida (2020) é a necessidade de se compreender as diferentes informações disponíveis atualmente (de mercado, clientes, concorrência etc.), de modo a aprimorar as atividades empresariais e trazer inovações aos negócios contábeis. Dantas, Araújo, Silva e Lagioia (2018) complementam que tradicionais práticas gerencias (por exemplo, orçamento e avaliação de desempenho) influenciam na capacidade de inovação das empresas, ressaltando o potencial dos profissionais contábeis na análise de informações e na consultoria de negócios tanto de clientes quanto próprios. Sobre os negócios contábeis, De Paula, Danjour, Medeiros e Añez (2015) apontam que o grau de inovação e de diferenciação entre as empresas no mercado contábil é caracterizado pelo uso de recursos tecnológicos nos processos, que trazem benefícios como otimização, agilidade, segurança, redução de custos, entre outros, para as atividades contábeis. Além dos recursos, os resultados de Scarpin, Mondini, Neumann e Machado (2011) apontam que um ambiente propício par o desenvolvimento de inovações necessita de um bom relacionamento interno, interação e compartilhamento de ideia, revelando outras habilidades requeridas do profissional contábil.

\section{Procedimentos Metodológicos}

Esta pesquisa, qualitativa e descritiva-exploratória, foca na descrição das características de potenciais modelos de negócios disruptivos existentes, atualmente, no mercado contábil brasileiro, a partir de um estudo de caso único e integrado. Essa definição de estudo de caso refere-se a um mesmo contexto para análise de unidades múltiplas (Yin, 2015). Dessa forma, o contexto analisado diz respeito ao mercado contábil brasileiro, mais especificamente, à disrupção dos modelos de negócios contábeis, que é um assunto que vem sendo debatido no mercado, mas ainda pouco explorado academicamente. Já os casos referem-se às empresas analisadas, que possuem traços de disrupção na descrição de seus negócios no mercado contábil. Em função da característica inovadora das empresas analisadas, outra classificação a ser destacada é quanto à peculiaridade desses casos (Yin, 2015), que se desviam dos demais negócios participantes do mercado contábil, justificando a escolha e a representatividade desses casos enquanto detentores da característica inovadora pelo que se conhece do mercado.

Os casos analisados foram compostos por empresas contábeis brasileiras, que estão sob o mesmo contexto de disrupção do mercado, bem como sujeitas a oportunidades e desafios semelhantes que emanam desse cenário. A fim de obter uma análise abrangente do mercado contábil brasileiro, foram analisadas empresas que prestam atividades em diferentes áreas da Contabilidade: Financeira, Gerencial, Tributária, Sistemas de Informação Contábil, Perícia e Auditoria. Buscou-se por empresas que desenvolvem atividades contábeis relacionadas às áreas mencionadas: escritório contábil (Financeira), consultoria gerencial (Gerencial), consultoria tributária (Tributária), empresa de software contábil (Sistemas de Informação Contábil), empresa de auditoria (Auditoria) e escritório de perícia (Perícia).

A seleção dos casos foi obtida por amostragem não probabilística e seu acesso deu-se por meio de duas técnicas: pesquisas no Google e indicação de especialistas. A pesquisa no Google foi realizada utilizando-se os termos modelo de negócio disruptivo (e possíveis derivações: modelo de negócio inovador 
e novo modelo de negócio) e contabilidade ou uma de suas áreas (financeira, gerencial, tributária, sistemas de informação contábil, perícia e auditoria). A partir dessas buscas, foram identificadas empresas com potenciais características disruptivas em seus negócios. Nessa etapa, foram selecionadas 3 empresas: uma da área Financeira, uma da área Tributária e uma da área de Sistemas de Informação Contábil. A segunda técnica contou com a contribuição de seis especialistas (profissionais acadêmicos), um de cada área da Contabilidade analisada, para a indicação de empresas contábeis com potenciais de disrupção em seus negócios. Nessa etapa foram selecionadas 3 empresas: uma da área Gerencial, uma da área de Perícia e uma da área de Auditoria. Ao total, foram selecionadas seis empresas, sendo todas localizadas na região Sul do Brasil. A partir dessa seleção, as unidades de análise definidas foram os gestores das empresas, que participam das decisões estratégicas, operacionais e financeiras do negócio, os quais foram contatados para participar da pesquisa.

Após a definição dos casos e das unidades de análise, partiu-se para a coleta de dados. Yin (2015) afirma que existem diversas formas para a coleta de dados em um estudo de caso, podendo combinar mais de um tipo de coleta no mesmo estudo, o que contribui para a amplitude e para a validade da pesquisa. Optou-se pela coleta de entrevistas, com diferentes atores, e de documentos institucionais. Foram realizadas entrevistas semiestruturadas com o gestor de cada empresa selecionada e coletados documentos dessas empresas (material de sites, blogs, newsletter, revistas, entre outros). Complementarmente, foram feitas entrevistas semiestruturadas com seis profissionais acadêmicos e seis profissionais de mercado (totalizando doze entrevistas, sendo dois especialistas de cada área). A intenção de entrevistar esses especialistas é justificada pela necessidade de descrição dos tradicionais modelos de negócios contábeis, para fins de comparação com os novos modelos analisados. A triangulação dessas entrevistas é uma estratégia para representar o campo, a partir do relato de atores com interesses distintos (Flick, 2009b). Na seleção dos especialistas, utilizou-se da técnica de escolha por tipicidade, quando o pesquisador seleciona os sujeitos de análise com base nas informações disponíveis e no conhecimento prévio da população, pressupondo que a amostra selecionada possa representar o universo (Flick, 2009a).

O roteiro para as entrevistas com os profissionais acadêmicos e de mercado foi elaborado com base na literatura de Osterwalder e Pigneur (2011) sobre os elementos que compõem o Canvas, quais sejam: segmento de cliente atendido; forma de relacionamento; canais de comunicação; recursos; atividades/processos; parcerias; custos; receitas; e, proposta de valor (Apêndice A). Já o roteiro para as entrevistas realizadas com os gestores das empresas com potencial disruptivo (Apêndice B), além de utilizar a literatura sobre o Canvas (Osterwalder \& Pigneur, 2011), também utilizou a revisão de Schiavi et al. (2019) sobre as características dos modelos de negócios disruptivos. Essas características foram organizadas e ampliadas de modo a criar categorias de análise, sendo elas: avaliação e (re)adequação; utilização de inovações secundárias por economias emergentes; riscos; novos mercados; serviços com maior simplicidade, conveniência, acessibilidade e menor custo; novas formas de criação de valor; ameaças aos modelos tradicionais e estabilizados; comportamento empreendedor; padrões de modelos de negócios.

Após a coleta desse material, partiu-se para o tratamento e análise dos dados. As dezoito entrevistas foram gravadas (com o consentimento dos entrevistados, mantendo-se 0 anonimato das respectivas empresas, gestores e especialistas) e transcritas, a fim de permitir uma melhor operacionalização e manipulação de todo o material no software Nvivo 12. Os dados documentais também foram organizados e manipulados no Nvivo 12. Para a análise dos dados, utilizou-se da análise conteúdo, buscando descrever o significado dos dados qualitativos ao atribuir categorias para o material coletado em um quadro de codificação (ou code book) que apresenta todos os aspectos de descrição e interpretação (Schreier, 2013). Conforme exposto, o quadro de codificação foi construído a partir de códigos derivados da literatura sobre o Canvas e sobre os modelos de negócios disruptivos, exposto no Apêndice C. A partir desses códigos, utilizou-se o software Nvivo 12 para a identificação desses elementos nas entrevistas realizadas e nos documentos coletados, de forma a organizar sistematicamente o material de análise.

\section{Análise dos Resultados}

Os negócios examinados possuem potenciais disruptivos em sua estrutura, o que levou à análise mais detalhada desses casos. A empresa da área Financeira tem se mostrado inovadora ao trabalhar em um modelo de escritório online, oferecendo serviços contábeis obrigatórios para micro e pequenas empresas, via plataforma digital, $100 \%$ online e a baixo custo. Há 6 anos no mercado, é considerado o maior e mais inovador escritório contábil brasileiro, em virtude de sua contabilidade totalmente online e que alcança diferentes empresas no Brasil. A empresa da área Gerencial, apesar de sua tradicional estrutura enquanto uma empresa de consultoria contábil, diferencia-se por deixar os serviços de assessoria acessíveis (a nível de valores e análises) a micro e pequenas empresas, provendo seus clientes com diferentes informações que são disponibilizadas em softwares contábeis, de gestão e de comunicação, estando no mercado há 10 anos. A empresa da área Tributária é uma das firmas líderes dessa área, contando com mais de 70 escritórios no Brasil. Há 7 anos no mercado, essa empresa é pioneira no uso de Big Data, Inteligência Artificial e robótica nos processos de análise fiscal, que garantem eficiência na captura de regras fiscais e atualização de seu banco de dados tributários, permitindo que os consultores 
entreguem soluções tributárias de forma ágil e eficiente aos seus mais de 2.000 clientes.

A empresa da área de Sistemas de Informação Contábil oferece uma plataforma de controle financeiro de baixo custo a um segmento do mercado pouco atendido (micro e pequenas empresas), estando no mercado há 6 anos. Também considerado um dos negócios mais inovadores da área contábil, essa empresa possui sua plataforma instalada em mais de 800.000 empresas, conectando empresários com contadores, bancos, governo e outros. A empresa de Perícia destaca-se pelo uso de softwares, desenvolvidos internamente, para apoiar o processo de trabalho e facilitar a comunicação com clientes e parceiros, bem como pelo desenvolvimento de aplicativos (que permitem o cálculo automático de questões judiciais trabalhistas), nos últimos 6 anos. Por fim, a empresa de Auditoria analisada é um pequeno negócio que atua há 5 anos e que utiliza tecnologias de automação nos processos, permitindo a execução de testes de auditoria e análises mais eficientes, quando comparado com outras empresas de auditoria do mesmo porte. A Tabela 2 sumariza as informações apresentadas.

Tabela 2:

Legenda e descrição das unidades de análise

\begin{tabular}{|c|c|c|c|}
\hline $\begin{array}{l}\text { Legenda } \\
\text { (Gestor) }\end{array}$ & Área & Tipo de empresa & Descrição \\
\hline G_1 & Financeira & Escritório contábil online & $\begin{array}{l}\text { Modelo de negócio online para prestação de serviços } \\
\text { contábeis obrigatórios a micro e pequenas empresas, } \\
\text { via plataformas digitais e a baixo custo. }\end{array}$ \\
\hline G_2 & Gerencial & Consultoria gerencial & $\begin{array}{l}\text { Modelo de negócio com foco em serviços gerenciais } \\
\text { para micro e pequenas empresas. }\end{array}$ \\
\hline G_3 & Tributária & Consultoria tributária & $\begin{array}{l}\text { Modelo de negócio com foco em soluções tributárias } \\
\text { atualizadas para nichos específicos. }\end{array}$ \\
\hline G_4 & $\begin{array}{l}\text { Sistemas de Informação } \\
\text { Contábil }\end{array}$ & Empresa de software & $\begin{array}{l}\text { Oferta de plataforma financeira de baixo custo a micro } \\
\text { e pequenas empresas. } \\
\text { Escritório de perícia que desenvolveu aplicativo e }\end{array}$ \\
\hline G_5 & Perícia & Escritório de perícia & $\begin{array}{l}\text { sistema interno para apoiar os processos de trabalho e } \\
\text { de comunicação. }\end{array}$ \\
\hline G_6 & Auditoria & Empresa de auditoria & $\begin{array}{l}\text { Pequena empresa de auditoria que busca na } \\
\text { automação formas de deixar os processos mais } \\
\text { eficientes e seguros. }\end{array}$ \\
\hline
\end{tabular}

Para representar os relatos dos especialistas, também foram atribuídos códigos a cada um dos entrevistados. Os seis especialistas acadêmicos (EA) são professores que, além da experiência acadêmica, contam com experiência profissional na área analisada. Os especialistas acadêmicos receberam os códigos EA_1 a EA_6 (EA_1 para o especialista acadêmico da área Financeira, EA_2 para o da área Gerencial, EA_3 para o da área Tributária, EA_4 para o da área de Sistemas, EA_5 para o da área de Perícia e EA_6 para o da área de Auditoria). Já os seis especialistas de mercado (EM) são profissionais que trabalham na respectiva área analisada e em modelos tradicionais, que não apresentam traços de inovação. Os especialistas de mercado são indicados pelos códigos EM_1 a EM_6 (EM_1 para se referir ao especialista de mercado da área Financeira, EM_2 para o da área Gerencial, EM_3 para o da área Tributária, EM_4 para o da área de Sistemas, EM_5 para o da área de Perícia e EM_6 para o da área de Auditoria).

\subsection{Comparação entre modelos de negócios tradicionais e modelos de negócios disruptivos}

Inicialmente, observa-se que não há uniformidade em relação ao tipo de cliente atendido em cada um dos tradicionais modelos de negócios contábeis, tendo em vista a amplitude das atividades, as quais podem atender a diferentes clientes (desde a pequena até a grande empresa e de qualquer setor), consoante relato unânime dos especialistas (acadêmicos e de mercado). Já nos novos modelos, percebe-se que algumas empresas (como destacado pelos gestores da área Financeira G_1, Gerencial G_2 e de Sistemas G_4) preocupam-se em atender uma parcela do mercado de clientes menos atraentes ou de clientes não consumidores, buscando vantagem competitiva ao ofertar produtos e serviços de baixo custo a esse público. Além disso, o Gest_3 também destaca a preocupação em atender nichos, principalmente empresas de maior porte e do setor atacadista, que possuem demandas maiores em relação a questões tributárias. Tal fato é discutido em detalhe na subseção 4.2 .4 a seguir.

Outro elemento estratégico analisado trata do relacionamento da empresa com o cliente, bem como da forma de comunicação (por meio de canais). Conforme relato de todos os especialistas de mercado, os tradicionais modelos contábeis procuram ter um relacionamento próximo do segmento de cliente atendido, a fim de entender e prestar um serviço adequado e de acordo com a necessidade desse cliente (EM_1, EM_2, EM_3, EM_4, EM_5 e EM_6). Entretanto, os especialistas acadêmicos (EA_1, EA_4, EA_5 e EA_6) ressaltam que, muitas vezes, esse relacionamento próximo é mais evidente no início da prestação dos serviços e que, com o passar do tempo, esse relacionamento costuma a se distanciar. A exceção é evidente nas consultorias gerencias e tributárias (EA_2 e EA_3), nas quais o contador busca prestar assessoria continuamente aos clientes, evidenciando a figura do contador como um parceiro de negócio do cliente (Baron, 2016). Nesses casos, os tradicionais meios de comunicação, como telefone, $e$ mail e atendimento presencial, são as principais formas de comunicação destacadas pelos especialistas de 
mercado (EM_1, EM_2, EM_3, EM_4, EM_5 e EM_6).

Assim como os tradicionais modelos contábeis, os gestores das empresas com potenciais disruptivos revelam que procuram ter forte proximidade com seus clientes (G_1, G_2, G_3, G_4, G_5 e G_6). Isso porque os modelos de negócios disruptivos buscam dar atenção e sensibilizar seus consumidores, a fim de manter o segmento atendido e ampliar as cotas de mercado atendidas (Hwang \& Christensen, 2008). Considerando que alguns desses novos modelos de negócios trabalham em escala (Gest_1 e Gest_4), o uso de plataformas digitais auxilia a tornar o relacionamento mais próximo, através da divulgação das informações contábeis em tempo real, confirmando os resultados de Sebastian et al. (2017) sobre a inovação a partir do uso de plataformas. Diferentemente dos modelos tradicionais, todos gestores relatam maior utilização de tecnologias de comunicação (plataformas online e outros sistemas internos de comunicação) para manter contato com o cliente de forma rápida e acessível, além dos tradicionais meios de comunicação, como telefone e e-mail (G_1, G_2, G_3, G_4, G_5 e G_6).

Em relação aos recursos utilizados, é notável o destaque dado por todos os especialistas (acadêmicos e de mercado) ao conhecimento do contador como recurso central nos tradicionais modelos de negócios contábeis. Já nos novos negócios, todos gestores ressaltam a forte influência de novas e diferentes tecnologias apoiando as atividades e os processos contábeis desenvolvidos (G_1, G_2, G_3, G_4, G_5 e G_6), principalmente aquelas relacionadas às soluções digitais, como soluções em nuvem, plataformas digitais, softwares financeiros de integração, automação de processos e banco de dados (Knudsen, 2020). Enquanto nos tradicionais modelos contábeis a utilização dos recursos tecnológicos ainda é coadjuvante, nos novos modelos de negócios o papel das tecnologias é essencial para apoiar as atividades do profissional contábil, contribuindo com os achados de Bygren (2016) sobre o impacto atual das novas tecnologias nos negócios e nas atividades contábeis. Apesar do destaque das tecnologias nos novos modelos de negócios, o conhecimento do profissional contábil ainda é um recurso central para o desenvolvimento das atividades, conforme destacado por todos os gestores. Tais aspectos revelam características inerentes de empresas prestadoras de serviço, que necessitam da expertise técnica dos profissionais para a entrega dos serviços prometidos.

Nessa linha, os especialistas de mercado ressaltam que os recursos pessoais e tecnológicos (em menor escala) acabam sendo os principais elementos de custos dos tradicionais modelos de negócios contábeis (EM_1, EM_2, EM_3, EM_4, EM_5 e EM_6). Diante desses custos, a fonte de receitas dos serviços contábeis ofertados aos clientes (monetização) se dá, principalmente, sobre o orçamento de horas técnicas para a realização das atividades, como acontece nas empresas da área Gerencial, Tributária e de Auditoria (EM_2, EM_3 e EM_6). Excetuam-se desse caso os modelos de negócios da área Financeira (valor fixo ou percentual sobre o faturamento do cliente, EM_1), de Sistemas (venda ou locação de software, EM_4) e de Perícia (percentual sobre o valor da causa do cliente, EM_5).

De forma semelhante, os gestores dos novos modelos contábeis contam com os mesmos elementos de custos: tecnológicos (esse em maior escala, comparando com os tradicionais modelos contábeis) e pessoal (G_1, G_2, G_3, G_4, G_5 e G_6). Pela importância do profissional contábil na execução das atividades nos novos modelos de negócios, a monetização das entregas acaba acontecendo pelo pagamento de horas técnicas trabalhadas nas empresas da área Gerencial, Tributária e de Auditoria (G_2, G_3 e G_6), ou pelo percentual sobre a causa do cliente, no caso da empresa de Perícia (G_5), assim como ocorre nos tradicionais modelos. Entretanto, percebe-se uma tendência para a oferta de produtos e serviços de baixo custo, segundo exposto, principalmente, pelos gestores da área Financeira (G_1) e de Sistemas (G_4), no qual a monetização se dá na forma de "pacotes/mensalidades" proporcionais à necessidade de cada cliente. Esse fato será discutido detalhadamente na subseção 4.2.5 a seguir.

Sobre os processos (atividades-chave do modelo de negócios), o acesso às informações do cliente é a base para qualquer uma das atividades exercidas, tanto pelos tradicionais modelos de negócios quanto pelos novos modelos de negócios, conforme exposto pelos especialistas (acadêmicos e de mercado) e pelos gestores. Destaca-se, ainda, por parte de todos os gestores das novas empresas contábeis, a preocupação com o planejamento das atividades a serem executadas e o apoio das diferentes tecnologias utilizadas nos processos de recebimento, processamento e entrega das informações (G_1, G_2, G_3, G_4, G_5 e G_6). Sobre isso, percebe-se que as novas soluções tecnológicas exercem um importante papel não só na organização dos serviços, mas também na estruturação dos novos modelos contábeis (Dimitriu \& Matei, 2015, Chiu et al., 2019; Knudsen, 2020), de modo que a digitalização das informações influencia na estrutura do negócio, principalmente da área financeira e de sistemas (modelos online e digitais) (G_1 e G_4).

Complementando a questão dos processos, tanto os novos quanto os tradicionais modelos de negócios procuram parcerias, principalmente, com outros contadores e advogados para auxiliar em certas atividades, conforme destacado pelos especialistas (acadêmicos e de mercado) e pelos gestores. Ressaltase que a manutenção de alianças com parceiros tecnológicos não foi destacada por nenhum gestor das novas empresas contábeis, em decorrência do desenvolvimento das tecnologias utilizadas dentro dos próprios negócios.

Outro importante elemento estratégico analisado trata da entrega de valor ao cliente. Verifica-se, pelo relato dos especialistas, que os tradicionais modelos de negócios contábeis entregam propostas de 
valores a seus clientes baseadas em questões gerenciais e financeiras. As áreas Tributária (EA_3 e EM_3) e de Perícia (EA_5 e EM_5) realizam entregas de valor que refletem em aspectos financeiros, seja pela redução de perdas ou aumento de ganhos. Já as áreas Gerencial (EA_2 e EM_2), de Sistemas (EA_4 e EM_4) e de Auditoria (EA_6 e EM_6) têm suas entregas focadas em aspectos gerenciais, contribuindo com o processo de análise das informações, tomada de decisão e maior organização de controles internos e informacionais. Por outro lado, nota-se que as atividades que somente cumprem com requisitos obrigatórios (como no caso dos escritórios contábeis tradicionais, a partir do atendimento a questões fiscais, trabalhistas e societárias, por exemplo - EA_1 e EM_1) não entregam valor de forma tão impactante para alguns clientes, em comparação com entregas que refletem em questões financeiras (aumento dos ganhos ou redução das perdas) e gerenciais (apoio na tomada de decisão, organização informacional e de controles etc.).

Sobre as propostas de valor dos novos modelos de negócios contábeis, é possível notar algumas semelhanças e diferenças em relação aos tradicionais modelos de negócios. As áreas Tributária (G_3) e de Perícia (G_5) também realizam entregas de valor que refletem em aspectos financeiros do cliente. Contudo, nota-se que a empresa Tributária analisada desempenha suas atividades com foco maior em consultorias e no desenvolvimento de estratégias tributárias, como mapeamento de oportunidades tributárias e monitoramento automático de regras fiscais (G_3); ao contrário dos tradicionais modelos de negócios tributários, que dão mais enfoque para atividades de recuperação de créditos tributários e de revisão e apuração de tributos (EA_3 e EM_3).

As áreas Gerencial (G_2), de Sistemas $\left(G \_4\right)$ e de Auditoria (G_6) também têm suas entregas voltadas para aspectos gerenciais, contribuindo com o processo de tomada de decisão do cliente. Todavia, os gestores das empresas das áreas Gerencial (G_2) e de Sistemas (G_4) destacam-se ao tornarem essas entregas de valor mais acessíveis e viáveis aos segmentos de clientes que normalmente não usufruem desses produtos e serviços (como os micro e pequenos empresários). Já o gestor da empresa de Auditoria (G_6) destaca-se ao encaminhar sua empresa para um perfil mais consultivo, buscando não só apontar as deficiências salientadas no trabalho de auditoria, mas também contribuir com o negócio do cliente, respeitando os limites entre os trabalhos de auditoria e os trabalhos de consultoria.

Ainda, diferentemente dos tradicionais modelos de negócios da área Financeira, o qual se verificou que dependendo do cliente a entrega de valor não ocorre de forma tão marcante e efetiva (EM_1), no novo modelo de negócio da área Financeira a entrega de valor se dá ao realizar as obrigações legais de maneira mais rápida e acessível, trazendo mais agilidade para o cliente e simplificando suas operações em relação aos aspectos contábeis exigidos (G_1). A proposição de novas formas de criação de valor é um aspecto fundamental para os modelos de negócios disruptivos, por isso, na subseção 4.2.6, essa questão será discutida novamente. Com isso, nota-se que os modelos de negócios contábeis inovadores usam práticas semelhantes às que são empregadas pelos modelos tradicionais, mas inovam oferecendo a tecnologia como diferencial na forma de realização de suas atividades, modificando a proposta de valor na oferta dos serviços ou especializando o nicho de mercado, principalmente. A Figura 1 apresenta uma síntese das diferenças entre os elementos dos modelos tradicionais e inovadores.

\begin{tabular}{|c|c|c|c|c|}
\hline \begin{tabular}{|l|} 
Parcerias Principais \\
\end{tabular} & Atividades Principais & Proposta de Valor & Relacionamento & Segmento de Clientes \\
\hline \multirow[t]{3}{*}{$\begin{array}{l}\text { Tradicional: } \\
\text { - Contadores } \\
\text { - Advogados } \\
\text { - Foco no auxilio em } \\
\text { determinadas atividades. } \\
\text { Inovador: } \\
\text { - Contadores } \\
\text { - Advogados } \\
\text { - Foco no auxilio em } \\
\text { determinadas atividades. }\end{array}$} & \begin{tabular}{|l|} 
Tradicional: \\
- Recebimento da \\
informação/documentação. \\
Inovador: \\
- A tecnologia como \\
facilitadora da captura, \\
processamento e \\
entrega da informaçãol \\
documentação.
\end{tabular} & \multirow{3}{*}{$\begin{array}{l}\text { Tradicional: } \\
\text { - Baseada em questões } \\
\text { gerenciais e financeiras: } \\
\text { - redução de perdas ou } \\
\text { aumento de ganhos. } \\
\text { - análise de informações e } \\
\text { tomada de decisão. } \\
\text { - maior organização de } \\
\text { controles internos e } \\
\text { informacionais. } \\
\text { - Atendimento das obrigações } \\
\text { contábeis. } \\
\text { Inovador: } \\
\text { - Baseada em questões } \\
\text { gerenciais e financeiras. } \\
\text { - Contador como um } \\
\text { parceiro de negócio } \\
\text { - Acessibilidade para } \\
\text { nichos não explorados. } \\
\text { Conveniência no } \\
\text { atendimento das } \\
\text { obrigações contábeis. }\end{array}$} & $\begin{array}{l}\text { Tradicional: } \\
\text { - Relacionamento próximo. } \\
\text { Inovador: } \\
\text { - Relacionamento próximo. } \\
\text { - A própria tecnologia } \\
\text { como uma aliada ao } \\
\text { atendimento em escala. }\end{array}$ & \multirow{3}{*}{$\begin{array}{l}\text { Tradicional: } \\
\text { - Portfólio de clientes } \\
\text { amplo e diverso. } \\
\text { Inovador: } \\
\text { - Parcela de mercado } \\
\text { näo explorada. } \\
\text { - Nicho específico. } \\
\text { - Busca-se vantagem } \\
\text { competitiva. }\end{array}$} \\
\hline & \begin{tabular}{|l|} 
Recursos Principais \\
\end{tabular} & & Canais & \\
\hline & $\begin{array}{l}\text { Tradicional: } \\
\text { - Conhecimento contábil. } \\
\text { Inovador: } \\
\text { - Novas tecnologias } \\
\text { (plataformas digitais, } \\
\text { computação em nuvem, } \\
\text { softwares contábeis e } \\
\text { etc.) } \\
\text { - Conhecimento contábil. }\end{array}$ & & $\begin{array}{l}\text { Tradicional: } \\
\text { - Telefone } \\
\text { - E-mail } \\
\text { - Atendimento presencial } \\
\text { Inovador: } \\
\text { - Meios tradicionais (e-mail } \\
\text { e telefone) } \\
\text { - Plataformas digitais para } \\
\text { comunicação. }\end{array}$ & \\
\hline \multicolumn{2}{|r|}{ Estrutura de Custos } & \multicolumn{3}{|c|}{\begin{tabular}{|l} 
Fontes de Receita \\
\end{tabular}} \\
\hline \multicolumn{2}{|c|}{$\begin{array}{l}\text { Tradicional: } \\
\text { - Recursos pessoais. } \\
\text { - Recursos tecnológicos (em menor escala). }\end{array}$} & \multicolumn{3}{|c|}{$\begin{array}{l}\text { Tradicional: } \\
\text { - Orçamento de horas técnicas utilizadas para a atividade. } \\
\text { - Valor fixo por produto/serviço. } \\
\text { - Percentual sobre faturamento ou causa do cliente. }\end{array}$} \\
\hline \multicolumn{2}{|c|}{$\begin{array}{l}\text { Inovador: } \\
\text { - Recursos pessoais. } \\
\text { - Recursos tecnológicos (em maior escala). }\end{array}$} & \multicolumn{3}{|c|}{$\begin{array}{l}\text { Inovador: } \\
\text { - Orçamento de horas técnicas utilizadas para a atividade. } \\
\text { - Percentual sobre causa do cliente. } \\
\text { - Oferta de produtos e serviços de baixo custo. } \\
\text { - pacotes/mensalidades }\end{array}$} \\
\hline
\end{tabular}

Legenda: os termos destacados em negrito referem-se aos principais aspectos de diferenciaçâo entre os novos e os tradicionais modelos de negócios contábeis.

Figura 1 - Diferenças entre os modelos de negócios contábeis tradicionais e os inovadores 
Da síntese apresentada, evidencia-se que boa parte das práticas dos modelos inovadores não abandona aquilo já realizado nos modelos tradicionais, mas sim incorporam novas tecnologias digitais como uma estratégia para se aproximarem dos clientes e se manterem competitivos no mercado. O principal diferencial é a segmentação do mercado em nichos nem sempre explorados por modelos tradicionais. Para atendimento de tal mercado específico, altera-se o tipo de monetização, valorizando as ofertas de produtos e serviços mais acessíveis e de baixo custo; e se aposta na escalabilidade e na eficiência de processos, proporcionadas pela tecnologia. Essa estratégia visa a vantagem competitiva a partir da mudança na forma de relacionamento, de comunicação e de valor entregue, principalmente a partir de soluções como plataformas digitais, que contribuem significativamente tanto com o cliente (ao possibilitar a ele acesso a um produto/serviço de qualidade a baixo custo), quanto com os contadores (que tiram maior proveito das tecnologias em suas atividades).

\subsection{Análise das características disruptivas}

Esta seção analisa as características dos potenciais modelos de negócios disruptivos para a área contábil. A partir da revisão de Schiavi et al. (2019), ampliou-se as características levantada pelos autores, para se verificar na prática gerencial e no mercado contábil a participação de modelos disruptivos com a entrada de novas tecnologias.

\subsubsection{Avaliação e (re)adequação}

A primeira característica inerente aos modelos de negócios disruptivos trata da avaliação e (re)adequação dos modelos de negócios e dos produtos ou serviços ofertados, tendo em vista a exploração de uma nova tecnologia ou de uma inovação nas empresas (Schiavi et al., 2019). Isso porque as tecnologias e inovações disruptivas são mais bem aproveitadas quando combinadas com a inovação dos modelos de negócios (Christensen \& Raynor, 2003; Moore, 2004). Três das empresas analisadas, das áreas Financeira, Gerencial e de Sistemas, originaram seus modelos de negócios buscando uma melhor adequação para a exploração das tecnologias e inovações utilizadas, a fim de aproveitar as oportunidades criadas pelas mesmas, conforme destacado pelo G_4, "a empresa já nasceu assim e é até por isso que a gente consegue ser pioneira em muitas coisas, porque faz parte do DNA o que nós somos hoje, [...] por isso a gente tem velocidade e consegue inovar tão rápido".

A estruturação dos negócios das empresas da área Financeira e de Sistemas foi apoiada por diferentes tecnologias (principalmente, automação, plataformas digitais próprias e computação em nuvem) para permitir a oferta de produtos e serviços contábeis totalmente online. Tal fato possibilitou que a empresa da área Financeira se destacasse entre as empresas mais inovadoras do ano de 2017, ao oferecer serviços contábeis online de forma mais eficiente, acessível e a um baixo custo. Do mesmo modo, a empresa da área de Sistemas também vem se destacando no mercado contábil ao proporcionar uma plataforma online de gestão financeira de baixo custo aos seus clientes, que integra empresas, contadores, governo, bancos etc. Já a empresa da área Gerencial estruturou seu modelo de negócio de forma a proporcionar que o profissional contábil ficasse mais próximo do cliente. Desse jeito, a inovação no modelo de negócio se deu em termos de processos, eliminando a setorização das atividades e integrando o contador ao negócio do cliente, o qual se apoia na utilização de softwares de controle financeiro, alimentados pelos clientes ou de forma automática, e softwares de gestão para prover o cliente com informações contábeis, financeiras e gerenciais, sendo esses clientes micro e pequenos empresários que, em muitos casos, não possuem acesso a essa Contabilidade Gerencial.

O gestor da empresa Tributária destaca que a exploração de novas tecnologias exigiu uma avaliação e readequação do modelo de negócio: "a gente começou em um modelo de negócios mais tradicional, como empresa contábil, mas no momento que estruturou a nova marca da empresa, nesse modelo disruptivo, envolveu mudar, [...] e isso requer muito esforço, principalmente a nível comportamental das pessoas" (G_3). Em um primeiro momento, a empresa automatizou seus processos de captura de regras fiscais divulgadas nos Diários Oficiais, trazendo agilidade às atividades. Em um segundo momento, buscou a integração das regras fiscais e dos sistemas de seus clientes, criando um banco de dados, que associa as regras a diferentes produtos (nesse caso, o principal segmento de atuação da empresa é o atacadista, que lida com inúmeros produtos e constantes alterações), trazendo eficiência aos serviços prestados. Em um terceiro momento, o uso da inteligência artificial, no reconhecimento de imagens e na análise de textos, auxilia os consultores tributários na entrega de informações úteis e estratégias tributárias aos clientes. Já o gestor da empresa de Auditoria ressalta que as ferramentas tecnológicas permitiram identificar soluções mais eficientes para a condução do negócio, como soluções para automatização de processos e soluções para identificação de inconformidades em amostra. Entretanto, tal fato provocou alterações no negócio gradualmente: "a gente começou em um modelo bastante tradicional, [...] então mudou bastante, mas mudou de uma forma orgânica, não foi uma coisa tão consciente assim" (G_6).

A introdução de novas tecnologias não provocou alterações nos serviços nem no modelo de negócio da empresa de Perícia, implicando, somente, uma melhor organização interna do negócio, a partir 
de softwares desenvolvidos internamente e sob demanda das necessidades dos processos do escritório (com foco para gerenciamento de documentos, abertura de chamado etc.). Cabe destacar que a empresa vem desenvolvendo novos aplicativos para cálculos periciais, entretanto, ainda não se observa uma nova organização da empresa para melhorar a forma de exploração e comercialização dessa ferramenta.

\subsubsection{Utilização de inovações secundárias por economias emergentes}

Outra característica que pode ser observada nos modelos de negócios disruptivos de economias emergentes é a introdução de tecnologias e inovações provenientes de economias mais avançadas, por meio de inovações secundárias nos modelos de negócios (Wu et al., 2010). Sobre isso, o G_4 destaca que "o Brasil está de 3 a 5 anos atrás de países desenvolvidos, em relação à organização, a sistemas para gestão, a integrações, inclusive, em relação à Contabilidade". Nesse sentido, nota-se que o contexto contábil brasileiro ainda está distanciado das inovações para o mercado contábil, principalmente em termos de introdução de novas tecnologias para apoiar os processos de inovação na oferta dos produtos e serviços contábeis. Por isso, cinco das seis empresas analisadas destacam observar as inovações do mercado contábil internacional, procurando oportunidades que possam ser trazidas para o contexto brasileiro, comportamento destacado por Schiavi et al. (2019).

Nessa linha, foi destacada, principalmente, inovações em termos de ferramentas tecnológicas, "porque a velocidade de tradução da tecnologia, ou mesmo da adaptação de tecnologias de fora, é cada vez maior [...] e o teu valor vai estar em conseguir identificar a ferramenta certa para o problema antes de outras pessoas se darem conta de que essa ferramenta é útil" (G_6). Ainda, os gestores revelaram possuir muito cuidado ao adaptar as inovações para o contexto brasileiro, isso porque "o que vem pronto não vem redondo para aplicar e, às vezes, é muito melhor criar algo aqui, especificamente para a necessidade da empresa brasileira [...], então, se eu tenho uma série de tecnologias novas, ok, vamos usar as tecnologias como ferramentas, mas não usar ideias" (G_3). Somente o gestor da área de Perícias destacou não se preocupar em observar o contexto internacional de sua área, tendo em vista que, conforme destacado pelo entrevistado, "perícia só tem aqui, é só no Brasil, lá fora eles nem sabem do que a gente está falando" (G_5), apontando para o fato de que as diferenças nessa área entre os países dificultam o processo de comparação dos negócios.

\subsubsection{Riscos}

Outra característica refere-se aos riscos relacionados ao potencial de perturbação das inovações nos modelos de negócios disruptivos. Conforme destacado por Schiavi et al. (2019), o potencial de perturbação de uma inovação proveniente de uma nova tecnologia tende a ser mais limitado no curto prazo, tendo em vista as incertezas relacionadas ao uso dessas tecnologias. Já o potencial de perturbação de uma inovação que vem orientada pelo mercado tende a ser maior no curto prazo, uma vez que se procura atender a uma necessidade específica de determinado segmento.

Diante desse contexto, três empresas analisadas afirmaram perceber alguns riscos associados ao potencial de perturbação das inovações. Duas delas enxergavam riscos relacionados à entrada de uma nova tecnologia: "se eu visse alguém fazendo um aplicativo de perícia igual aquele, eu iria estar pensando por que eu não tive essa ideia" (G_5). Sendo destacado pelo G_4 algumas formas de amenizar esses riscos: "a gente começou com pequenas versões de programas, [...] a gente trabalhou muito com validação, [...] se funcionou, se entregou valor, então a gente desenvolvia, melhorava [...], existiam riscos, mas existiam metodologias para aprender". Já o entrevistado da empresa da área Gerencial afirmou perceber alguns riscos associados ao potencial de perturbação das inovações orientadas pelo mercado: "eu acho que ter assumido esse posicionamento de uma contabilidade mais acessível, mais próxima, podia gerar desconfiança da competência técnica" (G_2).

As demais empresas analisadas não perceberam riscos associados ao potencial de perturbação das inovações nos modelos de negócios disruptivos, sejam elas orientadas por novas tecnologias ou pelo mercado: "eu não vejo o risco com as novas tecnologias no negócio, só vejo oportunidade, oportunidade de fazer melhor para os clientes" (G_1) ou ainda "eu diria que o maior risco seria se a gente não tivesse buscado adaptação [...], daqui a pouco eu posso ter um concorrente oferecendo personalização maior que a minha por um custo muito menor" (G_6). Para essas empresas, as possibilidades que podem surgir com as diferentes inovações nos negócios compensam os riscos que possam surgir ao longo do tempo.

\subsubsection{Novos mercados}

A exploração de tecnologias e inovações emergentes dentro dos modelos de negócios disruptivos proporcionam a oferta de produtos e serviços que atendam novos mercados, sendo essa característica amplamente levantada na literatura, visto que tal fato possibilita a obtenção de vantagem competitiva (Schiavi et al., 2019). Diante desse contexto, os gestores das empresas das áreas Financeira, Tributária e de Sistemas, afirmaram que as novas tecnologias utilizadas em seus processos permitiram criar produtos e 
serviços que atendem, atualmente, novos segmentos de clientes: "foi através de novas tecnologias que a gente permitiu oferecer o serviço que a gente oferece hoje... na nuvem, para milhares de empresas e em várias cidades do país, o que não era possível" (G_1) e "eu diria que a gente até criou mercados que não existiam, criou necessidades que talvez as pessoas nem sabiam que tinham" (G_3).

Já a empresa da área Gerencial destaca que a inovação nos seus processos permitiu que o modelo de negócio atendesse um novo segmento de mercado, embora ainda receba clientes mais tradicionais: "eu tenho clientes muito tradicionais que gostam do meu modelo de entrega de serviço, mas eu entrei e peguei uma fatia de clientes, muitas startups, que já não conseguiam enxergar valor no modelo de contador tradicional que fica só entregando obrigações contábeis” (G_2). Por outro lado, as empresas da área de Auditoria e de Perícia, por possuírem um público bem delimitado, não passaram a atender novos mercados. Entretanto, os gestores dessas empresas destacam que o apoio das novas tecnologias permitiu uma maior visibilidade dos negócios no mercado, bem como maior contentamento dos clientes atendidos.

\subsubsection{Serviços com maior simplicidade, conveniência, acessibilidade e menor custo}

A utilização de novas tecnologias e processos de inovação pelos modelos de negócios disruptivos auxiliam a proporcionar produtos e serviços com maior simplicidade, conveniência, acessibilidade e menor custo (Schiavi et al., 2019). Essas características são evidenciadas, principalmente, nos modelos de negócios das áreas Financeira e de Sistemas, os quais ofertam serviços contábeis online e sistemas de controle financeiro (em escala, de forma online, a baixo custo e para micro e pequenas empresas), respectivamente: "esse é o fruto de todo um trabalho de investimento que a gente fez [...], a gente conseguiu dar mais simplicidade, praticidade e principalmente economia para o nosso cliente" (G_1) e "tudo o que existe em comum entre empresas que causam disrupção no mercado foi usado ou foi fator de diferenciação para a gente, mas o principal fator é ter sistema em nuvens, sistema que você acessa de casa, você acessa da empresa, você acessa do celular" (G_4).

Já as empresas da área Gerencial, Tributária e de Auditoria, destacam que o uso de novas tecnologias e de processos de inovação permitiu a oferta de serviços, principalmente relacionados a consultorias e a interpretações de dados, que trazem importantes retornos para os negócios dos clientes: "assertividade acho que é a palavra-chave, [...], o uso de novas tecnologias dá muito mais assertividade para o negócio e isso dá mais segurança para o cliente” (G_3). Nessa linha, apesar das novas tecnologias contribuírem para a redução de custos, o valor de consultorias dessas empresas ainda é competitivo nos segmentos de mercado atendidos: "reflete em redução de custos, com certeza, porque a gente faz muito mais com menos tempo, [...] a gente automatizou um trabalho muito grande em termos de manipulação de bases de dados" (G_6) e "eu acho que se oferece uma proposta por um preço mais justo, que a pessoa sabe e entende o que está pagando" (G_2). Dessa forma, as empresas destacam que o serviço apoiado por novas tecnologias e processos de inovação permite aproximar o contador de seu cliente, produzindo soluções mais acessíveis e compreensíveis, como sugerem Baron (2016) e Bygren (2016).

Porém, na empresa de Perícia, é possível observar que os serviços desenvolvidos não contam com essas características, sendo os softwares utilizados somente como uma forma de melhorar a comunicação entre empresa e cliente. Entretanto, tais características são esperadas dos aplicativos que vêm sendo desenvolvidos internamente pela empresa.

\subsubsection{Novas formas de criação de valor}

A proposta de valor é um elemento estratégico fundamental para as empresas, tendo em vista que é atendendo às necessidades e aos problemas dos clientes que se consegue a manutenção do negócio (Osterwalder \& Pigneur, 2011). Nesse caso, os modelos de negócios disruptivos possuem uma grande preocupação e atenção com o seu segmento de mercado selecionado, buscando novas formas de criação de valor que sensibilizem os consumidores e que diferencie a empresa no mercado (Schiavi et al., 2019). Assim, procurou-se identificar as propostas de valor das empresas analisadas.

Em relação à área Financeira, a empresa analisada realiza serviços contábeis online para micro e pequenas empresas, realizando todas as obrigações legais exigidas. Sobre a entrega de valor, o G_1 destaca: "eu acredito que o nosso serviço entrega valor sim, mas ainda a gente está trabalhando para ter certeza que a gente entrega muito bem a contabilidade para micro e pequenas empresas no básico". Percebe-se que a forma como a empresa entrega valor está pautada no atendimento de um segmento específico, trazendo mais acessibilidade a esse público (por meio de uma contabilidade de baixo custo que realiza as obrigações legais exigidas) e mais agilidade (ao fornecer o serviço via plataforma online). Dessa maneira, verifica-se que a proposta de valor é semelhante com a que já existe no mercado, em termos de execução das obrigações legais. Entretanto, a forma como a proposta de valor é entregue (contabilidade online e a baixo custo) foi modificada pela empresa para atender o segmento de mercado selecionado, buscando ser mais acessível e ágil.

Sobre a forma de criação de valor da empresa Gerencial, o G_2 ressalta: "eu aproximei a contabilidade gerencial das pessoas [...], porque antes o meu público, as micro e pequenas empresas, 
pagavam para o contador trabalhar para o governo, [...] então é todo um trabalho de reeducação do cliente, dele entender que o contador pode oferecer valor". Nessa linha, a proposta de valor está em atender a um segmento específico do mercado, que muitas vezes não é consumidor desse serviço, aproximando o contador do negócio do cliente, a fim de auxiliar nos processos de decisão. Novamente, a proposta de valor entregue é semelhante com a que já existe no mercado, modificando-se o público-alvo atendido e a forma como as soluções são apresentadas e trabalhadas para o micro e pequeno empresário.

No que diz respeito à criação de valor da empresa Tributária, o G_3 afirma: "qualquer modelo de negócio é criado para atender algum problema ou necessidade [...], na medida que os clientes evoluem em processos tecnológicos, eles querem usar seu tempo livre para outras coisas, [...] e por que nós não vamos nos adaptar ao que eles precisam?". Nessa linha, a empresa analisada busca novas formas de criação de valor ao automatizar algumas tarefas, como alocação de regras tributárias em softwares integrados e em cadastro de mercadorias, trazendo maior agilidade e segurança aos procedimentos inerentes à tributação dos clientes. Além disso, essa automatização das atividades permite aos profissionais exercerem papéis de consultores, elaborando estratégias tributárias que impactam no efeito financeiro e entregando soluções de alto valor agregado ao cliente.

Já a empresa de Sistemas busca, por meio da plataforma de controle financeiro produzida, entregar novas formas de valor ao auxiliar na produção de informações para a gestão, trazendo maior organização, controle e produtividade aos micros e pequenos empresários, que muitas vezes não são consumidores desse tipo produto. Assim, por oferecer um produto de baixo custo, acessível e que atende a um novo mercado, a empresa procura, constantemente, não só entregar o valor proposto, mas trazer ainda mais melhorias para o produto, aumentando a boa experiência de uso do cliente com o sistema: "a maior parte do nosso time é das pessoas que estão melhorando a plataforma a cada dia, então a gente está lançando mais integrações, [...] o formato de envio da informação financeira para a contabilidade também evolui, a gente está buscando sempre novas formas de ser mais automatizados" (G_4).

Por sua vez, a empresa de Auditoria tem sua entrega de valor pautada no apontamento das deficiências salientadas no trabalho de auditoria, assemelhando-se aos tradicionais modelos de negócios da área de Auditoria. Contudo, percebe-se que a empresa procura exercer um perfil mais consultivo, buscando contribuir com o negócio do cliente por meio de avaliações tributárias, contábeis ou financeiras, respeitando os limites entre os trabalhos de auditoria e de consultoria. Quanto à empresa da área de Perícia, não foram destacadas novas e diferentes formas de criação de valor pelo gestor, visto que a entrega de valor está pautada no efeito financeiro para o cliente (aumento do ganho ou redução da perda), assim como os demais modelos de negócios nessa área.

\subsubsection{Ameaças aos modelos tradicionais e estabilizados}

Outra característica levantada por Schiavi et al. (2019) e bastante marcante dos modelos de negócios disruptivos é o fato dos novos modelos representarem ameaças diretas e severas para a manutenção dos modelos tradicionais e estabilizados no mercado. Nesse sentido, como destacado pelo G_4, "qualquer estratégia que ajude a ganhar mercado, ela é uma ameaça para os concorrentes". Por isso, percebe-se que os negócios das áreas Financeira e de Sistemas, ao ofertarem produtos e serviços de baixo custo em escala, estão conseguindo atrair muitos consumidores, bem como a atenção de outras empresas concorrentes em cada área. Embora haja esse impacto no mercado, as empresas destacam que seus objetivos não estão pautados em desestabilizar os negócios existentes, mas sim em proporcionar um melhor atendimento ao mercado.

Já os gestores das empresas das áreas Gerencial e Tributária destacam que seus modelos de negócios não causaram fortes impactos aos concorrentes: "eu diria que o nosso modelo, assim como alguns modelos disruptivos, vem para completar o espaço que não existia, vem para atender uma necessidade que ninguém viu antes em nenhum modelo tradicional, ou que não se conseguiria fazer no modelo tradicional" (G_3). Por fim, os gestores das áreas de Perícia e de Auditoria ressaltam que as inovações tecnológicas em seus modelos de negócios serviram mais como uma forma de organizar as empresas internamente e trazer maior agilidade às atividades. Ainda, o gestor do negócio de Perícia destaca que o lançamento do aplicativo que a empresa está desenvolvendo pode representar um impacto maior no mercado por representar uma inovação maior para essa área.

\subsubsection{Comportamento empreendedor}

A questão de assumir um comportamento empreendedor é uma característica fundamental dos modelos de negócios disruptivos e levantada na revisão de Schiavi et al. (2019). Isso porque assumir um comportamento empreendedor para analisar o mercado e o próprio negócio, buscando novas formas de entregar valor ao consumidor, é importante para os gestores aproveitarem as oportunidades e fugirem das ameaças que vêm com os novos modelos de negócios. Nessa linha, ainda nos achados de Schumpeter (1934), a figura do empreendedor é vista como o agente econômico que não hesita em quebrar as rotinas e impulsionar os demais agentes econômicos a evoluir. 
Dessa maneira, os gestores de todas as empresas destacam que é uma preocupação esse comportamento dentro de seus negócios, revelando a importância de se pensar em inovações para os negócios: "para quem quer trabalhar no modelo disruptivo, empreender é fundamental, se tu não aplicares recurso em pesquisa, ter mentes brilhantes pensando, olhando necessidades, olhando cada centímetro quadrado da oportunidade que existe para desenvolver uma coisa nova, não funciona" (G_3). Observa-se, ainda, a preocupação dos gestores em pensar nas ameaças que possam surgir no mercado de atuação. Isso é percebido, principalmente, no discurso do gestor do negócio de Perícia, o qual vê incertezas na condução do negócio no futuro e, por isso, vem procurando soluções alternativas para se manter no mercado: "a área está sofrendo transformações e essas ameaças vêm, além da própria concorrência, de preço, [...] também com essa situação da reforma" (G_5).

\subsubsection{Padrões de modelos de negócios}

Na mesma linha da característica anterior, padrões de modelos de negócios podem ser utilizados para a interpretação do ambiente e para a antecipação sobre a forma de se fazer o negócio pretendido. Sobre isso, todos os gestores destacaram observar diferentes negócios como uma forma de analisar o mercado, a fim de verificar as possibilidades de negócio que poderão dar certo ou não no futuro. Nesse sentido, o gestor da empresa Tributária ressalta a importância de se ter como referência diferentes fontes para análise de mercado e de negócio: "a gente não define o que vai fazer nem olhando só internamente, nem conversando só com o cliente, nem olhando só para fora, a gente faz um mix de tudo isso" (G_3).

Ainda, nota-se que alguns modelos disruptivos presentes no mercado contábil atual são referências para alguns gestores: "eu vejo muitas startups bem interessantes, na linha de serviço contábil, altamente acessíveis e com uma qualidade bastante razoável, nas quais, para o tipo de serviço que elas oferecem, o negócio é escalável mesmo, tu estás resolvendo o problema de um monte de gente a um custo baixo". Entretanto, verifica-se que certas dificuldades são apontadas para a replicação desses modelos disruptivos em algumas áreas de atuação da Contabilidade, como aquelas voltadas para trabalhos gerenciais e de consultorias.

\subsection{Síntese dos aspectos disruptivos nos modelos de negócios contábeis}

Conforme exposto anteriormente, algumas características dos modelos de negócios disruptivos são mais marcantes e evidentes em determinadas empresas contábeis do que em outras, em decorrência, na maior parte das vezes, das atividades realizadas em cada área analisada. Com isso, a Figura 2 visa sintetizar a presença dos aspectos disruptivos nos modelos de negócios contábeis discutidos.

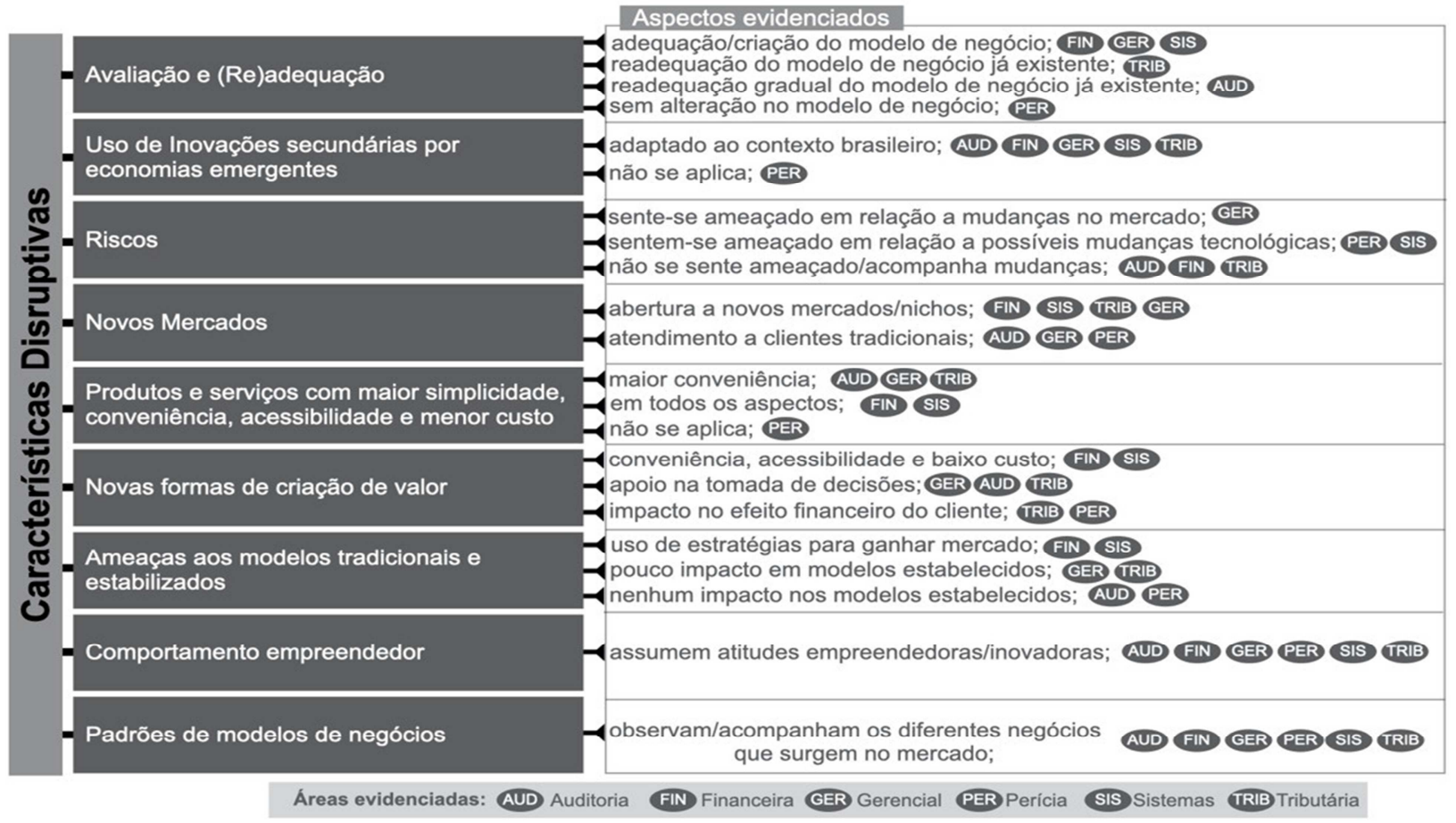

Figura 2 - Síntese dos aspectos disruptivos nos modelos de negócios contábeis

Percebe-se que as empresas da área Financeira e da área de Sistemas atendem às principais características dos modelos disruptivos. São empresas que adequaram seus negócios, visando uma melhor exploração das novas tecnologias, principalmente em nível de plataformas online, computação em nuvem e 
automatização, para oferecer produtos e serviços a um segmento específico do mercado: micro e pequenas empresas (segmento não atrativo ou de não consumidores). Esses resultados vão ao encontro das pesquisas de Baron (2016) e Bygren (2016), as quais ressaltam que as mudanças estratégicas nas estruturas empresariais e nas atividades contábeis são necessárias para melhorar a experiência do cliente. Ainda, o destaque dos aspectos tecnológicos corrobora o estudo de De Paula et al. (2015), que aponta a diferenciação e a inovação dos negócios contábeis pela introdução desses recursos nos processos.

A proposta de uma contabilidade online (pela empresa da área Financeira) e a de um sistema para controle financeiro (pela empresa da área de Sistemas) trouxeram novas propostas de valor ao mercado, como maior acessibilidade a esses produtos e serviços, maior agilidade (interação online) e maior organização informacional. Esses achados demonstram que cada vez mais tarefas de rotina, como entrada de dados e escrituração contábil, são processos de trabalhos vulneráveis à digitalização e à automação, corroborando as tendências apresentadas por Cokins e Angel (2017). Além disso, verifica-se que esses dois modelos de negócios ofertam produtos e serviços mais simples, convenientes e a baixo custo, tornando esses negócios escaláveis no mercado. A presença dessas atuais estruturas de negócios ressalta o processo de criação ou readequação das estruturas tradicionais, algo recomendado por Chesbrough e Rosenbloom, (2002), quando as oportunidades proporcionadas pelas novas tecnologias não se encaixam nos modelos de negócios existentes.

Em relação aos demais negócios analisados, percebe-se que as áreas Gerencial, Tributária e de Auditoria possuem algumas características dos modelos de negócios disruptivos, evidenciando a preocupação dessas empresas em inovar diante das mudanças no mercado contábil, como aponta Almeida (2020). Todavia, por tratar de negócios que realizam atividades diferenciadas para cada cliente, a escalabilidade torna-se um empecilho para essas empresas, uma vez que essa é uma das principais características que permitem os negócios disruptivos impactarem todo um mercado e desestabilizarem os concorrentes.

Mesmo assim, verifica-se que os negócios da área Gerencial, Tributária e de Auditoria se aproveitam de novas tecnologias em seus processos e atividades para oferecerem serviços de consultoria de alto valor agregado (serviço amplamente requisitado na economia digital), achados também ressaltados por Pan e Seow (2016) e Ransbotham e Kiron (2017). Já a área de Perícia, por se tratar de uma área com atividades bem restritas a um público também bem definido, é a que apresenta menos características de disrupção nos negócios. Apesar disso, verifica-se que a inovação nos negócios já é observada e pensada pelos gestores como uma forma de fugir das ameaças futuras, como a reforma trabalhista, por exemplo.

\section{Considerações Finais}

Este artigo atingiu seu objetivo ao descrever as características de potenciais modelos de negócios disruptivos existentes, atualmente, no mercado contábil brasileiro. Isso porque, nos últimos anos, as empresas nessa área vêm sofrendo constantes mudanças (Guthrie \& Parker, 2016), sendo a entrada de novas tecnologias nos negócios a grande influenciadora dessa quebra de paradigma (Bygren, 2016). Entretanto, a tecnologia por si só não é o agente causador de perturbações no mercado, mas sim a forma como ela é explorada dentro dos modelos de negócios, para melhor atender às necessidades dos clientes (Christensen \& Raynor, 2003). Diante disso, foram analisados os modelos de negócios de seis empresas contábeis com potenciais disruptivos em seus negócios.

De modo geral, destaca-se a forte influência de novos recursos tecnológicos apoiando as atividades e os processos contábeis, permitindo ao contador dois caminhos para a inovação de seus negócios: 1) atender em escala o mercado e proporcionar soluções para novos clientes (por exemplo, contabilidade online e sistemas financeiros simplificados); e 2) estar mais próximo do cliente e entregar atividades de maior valor agregado, como consultorias, estratégias de negócios, apoio na tomada de decisão etc. Sobre as características disruptivas, nota-se que algumas empresas estão mais próximas de serem consideradas potenciais modelos de negócios disruptivos no mercado contábil, como as empresas da área Financeira e de Sistemas. Essas duas empresas destacam-se pela oferta, em escala, de novos produtos e serviços com valor agregado a um público menos atrativo: micro e pequenas empresas. Tal fato permitiu que essas empresas alcançassem uma quota do mercado contábil nacional de forma rápida e intensa. E a disrupção do negócio torna-se evidente pelo uso de novas tecnologias como fonte de modificação e diferenciação dos negócios, e não somente no apoio das atividades realizadas.

Apesar da presença desses negócios no mercado atualmente, os modelos tradicionais ainda estão sendo pouco perturbados por esses novos negócios que surgem, conforme destacado pelos profissionais de mercado entrevistados. Contudo, a entrada de tais negócios serve de alerta para as mudanças no cenário contábil empresarial. Nessa linha, verifica-se que as necessidades dos clientes estão se alterando e que cada vez mais será exigido do profissional contábil respostas rápidas e eficientes para os problemas dos clientes. Tal fato ressalta os achados de Hood (2017) que afirma que a quantidade de profissionais preparada para lidar com as mudanças atuais do mercado contábil ainda é baixa. O profissional contábil, seja nos modelos tradicionais ou nos novos modelos de negócios, exerce papel fundamental tanto na organização empresarial quanto na execução das atividades contábeis. Diante das mudanças do cenário 
contábil, o desafio dos profissionais contábeis será determinado pela capacidade de buscar por novas formas de criação de valor aos clientes, por meio da oferta de novos serviços e produtos em modelos de negócios inovadores (Baron, 2016).

Considera-se que esta pesquisa contribui com o campo ao apresentar características de potenciais modelos de negócios disruptivos contábeis, analisando essas características em casos contemporâneos e de destaque no mercado contábil atual. Com isso, analisando os resultados sistematizados na Figura 2, outros negócios da área podem se espelhar e buscar as estratégias de tais modelos de negócios. Essas análises permitem trazer para o campo e para os gestores um contexto maior sobre as mudanças do cenário contábil, visto que retratam aspectos de gestão dos novos negócios que são referências no mercado contábil atual. Esta pesquisa ainda contribui com a teoria ao apresentar um estudo empírico sobre o processo de inovação dos negócios contábeis, visto que o conservadorismo da profissão e a aversão a mudanças na condução dos negócios são aspectos que distanciam a inovação do contexto contábil (Chang, Hilary, Kang, \& Zhang, 2013). Ainda, esta pesquisa avança os achados de Schiavi et al. (2019), ao traduzir a revisão dos autores em categorias para análise de dados empíricos.

Como limitação, a presente pesquisa, ao realizar um estudo de caso, não permite que seus resultados sejam generalizados. Entretanto, buscou-se minimizar essas limitações com justificativas metodológicas que embasassem a escolha pela pesquisa qualitativa e feita por estudo de caso único, integrado e peculiar, em função do atual contexto de mudança do mercado contábil (impactados pela entrada de novas tecnologias e negócios) e da representatividade dos casos enquanto característicos dos aspectos analisados ao tomar por comparação os outros negócios presentes no mercado contábil. Por fim, recomenda-se, para estudos futuros, explorar algumas das novas tecnologias, como banco de dados, automação, cloud computing, entre outras, que estão sendo utilizadas nos negócios contábeis, a fim de compreender como essas tecnologias reorganizam os negócios e a profissão contábil, bem como são aceitas e utilizadas pelos seus usuários.

\section{Referências}

Almeida, J. E. F. (2020). Revolução tecnológica no mundo dos negócios e algumas oportunidades e desafios na área contábil. Revista de Contabilidade e Organizações, 14, e165516. doi: https://doi.org/10.11606/issn.1982-6486.rco.2020.165516

Baden-Fuller, C., \& Morgan, M. S. (2010). Business models as models. Long Range Planning, 43(2-3), 156171. doi: https://doi.org/10.1016/j.Irp.2010.02.005

Baron, J. (2016). Disruptive trends accelerating for the accounting profession. Thomson Reuters.

Basova, A. (2017). Accounting-analytical model of innovation-active business entities. Advances in Economics, Business and Management Research, 38, 40-46. doi: https://doi.org/10.2991/ttiess-17.2017.7

Bower, J. L., \& Christensen, C. M. (1995). Disruptive technologies: Catching the wave. Harvard Business Review, 73(1), 43-53.

Bygren, K. (2016). The digitalization impact on accounting firms business models. Thesis (Master of Science) - School of Industrial Engineering and Management, Kungliga Tekniska Högskolan, Stockholm, Sweden. Recovered from https://www.diva-portal.org/smash/get/diva2:939040/FULLTEXT01.pdf

Chang, X., Hilary, G., Kang, J. K., \& Zhang, W. (2013). Does accounting conservatism impede corporate innovation?. INSEAD Working Paper Series, 35, 01-46.

Chartered Accountants. (2015). Disruptive technologies risks, opportunities - can new zealand make the most of them?. Chartered Accountants Australia and New Zealand.

Chesbrough, H., \& Rosenbloom, R. S. (2002). The role of the business model in capturing value from innovation: evidence from Xerox Corporation's technology spin-off companies. Industrial and Corporate Change, 11(3), 529-555. doi: https://doi.org/10.1093/icc/11.3.529

Chiu, V., Liu, Q., Muehlmann, B., \& Baldwin, A. A. (2019). A bibliometric analysis of accounting information systems journals and their emerging technologies contributions. International Journal of Accounting Information Systems, 32, 24-43. doi: https://doi.org/10.1016/j.accinf.2018.11.003

Christensen, C. M., \& Raynor, M. (2003). The innovator's solution: creating and sustaining successful growth. Cambridge: Harvard Business School Press. 
Cokins, G., \& Angel, S. (2017). The Disruptive Impact of the Digital Revolution on Accounting. Crunchbase Icrunchdata.

Dantas, I. C., de Araújo, J. G., da Silva, L. V. B., \& Lagioia, U. C. T. (2018). Práticas gerenciais e inovação: um estudo em empresas do porto digital do Recife (PE). Revista Contemporânea de Contabilidade, 15(35), 48-68. https://doi.org/10.1590/S1413-73722003000100017

De Paula, L. P. D., Danjour, M. F., Medeiros, B. C., \& Añez, M. E. M. (2015). Inovações em processos de tecnologia: Um estudo de caso em uma empresa de contabilidade da cidade do Natal/RN. Holos, 6, 196209. doi: https://doi.org/10.1590/S1413-73722003000100017

Dimitriu, O., \& Matei, M. (2015). Cloud accounting: a new business model in a challenging context. Procedia Economics and Finance, 32, 665-671. doi: https://doi.org/10.1016/S2212-5671(15)01447-1

Flick, U. (2009a). Desenho da pesquisa qualitativa. Porto Alegre: Artmed, 2009.

Flick, U. (2009b). Qualidade na pesquisa qualitativa. Porto Alegre: Artmed, 2009.

Frey, C. B., \& Osborne, M. A. (2017). The future of employment: How susceptible are jobs to computerisation?. Technological Forecasting and Social Change, 114, 254-280. doi:

https://doi.org/10.1016/j.techfore.2016.08.019

Gelinas Jr, U. J., \& Gogan, J. L. (2006). Accountants and emerging technologies: A case study at the United States Department of the Treasury Bureau of Engraving and Printing. Journal of Information Systems, 20(2), 93-116. doi: https://doi.org/10.2308/ijs.2006.20.2.93

Guthrie, J., \& Parker, L. D. (2016). Whither the accounting profession, accountants and accounting researchers? Commentary and projections. Accounting, Auditing \& Accountability Journal, 29(1), 02-10. doi: https://doi.org/10.1108/AAAJ-10-2015-2263

Hwang, J., \& Christensen, C. M. (2008). Disruptive innovation in health care delivery: a framework for business-model innovation. Health Affairs, 27(5), 1329-1335. doi: https://doi.org/10.1377/hlthaff.27.5.1329

Hood, T. (2017). The Future-Ready CFO: Chief Future Officer. Business Learning Institute.

Knudsen, D. R. (2020). Elusive boundaries, power relations, and knowledge production: A systematic review of the literature on digitalization in accounting. International Journal of Accounting Information Systems, 36, 1-22. doi: https://doi.org/10.1016/i.accinf.2019.100441

Markides, C. (2006). Disruptive innovation: in need of better theory. Journal of Product Innovation Management, 23(1), 19-25. doi:10.1111/j.1540-5885.2005.00177.x

Metallo, C., Agrifoglio, R., Schiavone, F., \& Mueller, J. (2018). Understanding business model in the Internet of Things industry. Technological Forecasting and Social Change, 136, 298-306. doi:

https://doi.org/10.1016/j.techfore.2018.01.020

Mitchell, D. W., \& Coles, C. B. (2004). Business model innovation breakthrough moves. Journal of Business Strategy, 25(1), 16-26. doi: https://doi.org/10.1108/02756660410515976

Moore, G. (2004). Darwin and the demon: innovating within established enterprises. Harvard Business Review, 82(7-8), 86-93.

Osterwalder, A., \& Pigneur, Y. (2011). Business model generation - Inovação em modelos de negócios. Rio de Janeiro: Alta Books.

Pan, G., \& Seow, P. S. (2016). Preparing accounting graduates for digital revolution: a critical review of information technology competencies and skills development. Journal of Education for Business, 91(3), 166175. doi: https://doi.org/10.1080/08832323.2016.1145622

Ransbotham, S., \& Kiron, D. (2017). Analytics as a source of business innovation: the increased ability to innovate is producing a surge of benefits across industries. MIT Sloan Management Review, 58(3).

Remane, G., Hanelt, A., Nickerson, R. C., \& Kolbe, L. M. (2017). Discovering digital business models in 
traditional industries. Journal of Business Strategy, 38(2), 41-51. doi: https://doi.org/10.1108/JBS-10-2016$\underline{0127}$

Scarpin, M. R. S., Mondini, L. C., Neumann, M., \& Machado, D. D. N. (2011). Desenvolvimento de um ambiente propício para inovação no setor de serviços: uma análise em empresas de serviços contábeis do vale do Itajaí-SC. Revista de Contabilidade e Organizações, 5(13), 91-108. doi: https://doi.org/10.11606/rco.v5i13.34806

Schiavi, G. S., Behr, A., \& Marcolin, C. B. (2019). Conceptualizing and qualifying disruptive business models. RAUSP Management Journal, 54(3), 269-286. doi: https://doi.org/10.1108/RAUSP-09-2018-0075

Schreier, M. (2013). Qualitative content analysis. In U. Flick (Ed.), The SAGE handbook of qualitative data analysis. London: Sage, 170-183.

Schumpeter, J. (1934). Theory of economic development. Cambridge: Harvard University Press.

Sebastian, I., Ross, J., Beath, C., Mocker, M., Moloney, K., \& Fonstad, N. (2017). How Big Old Companies Navigate Digital Transformation. MIS Quarterly Executive, 16(3), 197-213.

Wu, X., Ma, R., \& Shi, Y. (2010). How do latecomer firms capture value from disruptive technologies? A secondary business-model innovation perspective. IEEE Transactions on Engineering Management, v. 57, 51-62. doi: https://doi.org/10.1109/TEM.2009.2033045

Yin, R. K. (2015). Estudo de caso: planejamento e métodos. 5. ed. Porto Alegre: Bookman.

APÊNDICE A - Roteiro de entrevista para os profissionais acadêmicos e de mercado

1. A empresa que atua na área (Financeira, Gerencial, Tributária, Sistemas de Informação Contábil, Auditoria ou Perícia) tem como alvo qual tipo de cliente? (Osterwalder \& Pigneur, 2011)

2. Como você resumiria o relacionamento desse tipo de empresa com seus clientes? (Osterwalder \& Pigneur, 2011)

3. Como você resumiria a forma de comunicação desse tipo de empresa com seus clientes (a partir de canais de distribuição e comunicação)? (Osterwalder \& Pigneur, 2011)

4. Qual o valor proporcionado ao cliente diante das entregas realizadas por esse tipo de empresa? (Osterwalder \& Pigneur, 2011)

5. Quais os processos-chave utilizados por esse tipo de empresa? (Osterwalder \& Pigneur, 2011)

6. Quais os recursos-chave utilizados por esse tipo de empresa? (Osterwalder \& Pigneur, 2011)

7. Como você descreveria a rede de parceria desse tipo de empresa com outros parceiros externos? (Osterwalder \& Pigneur, 2011)

8. Qual o modelo de custos (ou elementos de custo) utilizado(s) por esse tipo de empresa?

(Osterwalder \& Pigneur, 2011)

9. Qual o modelo de receita utilizado por esse tipo de empresa? (Osterwalder \& Pigneur, 2011)

APÊNDICE B - Roteiro de entrevista para os gestores de potenciais modelos de negócios disruptivos 1. A sua empresa que atua na área (Financeira, Gerencial, Tributária, Sistemas de Informação Contábil, Auditoria ou Perícia) tem como alvo qual tipo de cliente? (Osterwalder \& Pigneur, 2011)

2. Como você resumiria o relacionamento da sua empresa com os clientes? (Osterwalder \& Pigneur, 2011)

3. Como você resumiria a forma de comunicação da sua empresa com os clientes (a partir de canais de distribuição e comunicação)? (Osterwalder \& Pigneur, 2011)

4. Qual o valor proporcionado ao cliente diante das entregas realizadas por sua empresa? (Osterwalder \& Pigneur, 2011)

5. Quais os processos-chave utilizados por sua empresa? (Osterwalder \& Pigneur, 2011)

6. Quais os recursos-chave utilizados por sua empresa? (Osterwalder \& Pigneur, 2011)

7. Como você descreveria a rede de parceria de sua empresa com outros parceiros externos? (Osterwalder \& Pigneur, 2011)

8. Qual o modelo de custos (ou elementos de custo) utilizado(s) por sua empresa? (Osterwalder \& Pigneur, 2011)

9. Qual o modelo de receita utilizado por sua empresa? (Osterwalder \& Pigneur, 2011)

10. Você percebeu, em sua empresa, que a exploração de uma nova tecnologia ou de uma inovação exigiu a avaliação e readequação do modelo de negócio e dos produtos/serviços ofertados para seu melhor aproveitamento? Comente. (Schiavi et al., 2019)

11. Você percebeu, em sua empresa, que a exploração de uma nova tecnologia ou de uma inovação dentro de um novo modelo de negócio - proporcionou a oferta de produtos/serviços que atendiam novos mercados, possibilitando a obtenção de vantagem competitiva e a desestabilização das empresas até 
então dominantes? Comente. (Schiavi et al., 2019)

12. Você acredita que a utilização de tecnologias e/ou inovações disruptivas trouxe uma proposta de valor diferente para o mercado, bem como proporcionou produtos e serviços com maior simplicidade, conveniência, acessibilidade e menor custo? Comente. (Schiavi et al., 2019)

13. Você enxerga, em sua empresa, que há uma preocupação e atenção do novo modelo de negócio com o segmento de mercado selecionado, buscando novas formas de criação de valor que sensibilizem os clientes-alvo? Comente. (Schiavi et al., 2019)

14. Quanto aos riscos associados à introdução de novas tecnologias e/ou de outros processos de inovação, quais riscos você percebeu em relação ao seu negócio? (Schiavi et al., 2019)

15. Você acha que a introdução de novos modelos de negócios no mercado representou ameaças diretas e severas para a manutenção dos modelos tradicionais e estabilizados? Comente. (Schiavi et al., 2019)

16. Você acredita que possuir um comportamento empreendedor para analisar o mercado e o negócio é fundamental para aproveitar as oportunidades e fugir das ameaças que vem com os novos modelos de negócios? Esse comportamento é adotado? Comente.(Schiavi et al., 2019)

17. Você acha que a análise de padrões de modelos de negócios pode ser utilizada para a interpretação do ambiente e para a antecipação sobre a forma de se fazer o negócio pretendido? Vocês analisaram outros negócios inovadores nessa área?(Schiavi et al., 2019)

18. Você acredita que empresas de economias emergentes podem introduzir tecnologias e inovações de economias mais avançadas, por meio de inovações secundárias, nos modelos de negócios? Isso aconteceu em sua empresa? (Schiavi et al., 2019)

\begin{tabular}{|c|c|}
\hline Código & Descrição \\
\hline Proposta de Valor & $\begin{array}{l}\text { Uma empresa busca resolver os problemas dos clientes e satisfazer suas necessidades com } \\
\text { propostas de valor em seus produtos e/ou serviços. }\end{array}$ \\
\hline Segmentos de Clientes & $\begin{array}{l}\text { Os clientes podem ser segmentados em diferentes grupos, de acordo com determinadas } \\
\text { características, e uma empresa pode servir a um ou diversos segmentos de clientes. }\end{array}$ \\
\hline Relacionamento com Clientes & As empresas estabelecem e mantêm relacionamentos com clientes de forma a retê-los. \\
\hline Canais & $\begin{array}{l}\text { As empresas desenvolvem diferentes canais de comunicação, de distribuição e de vendas para } \\
\text { comunicar e levar suas propostas de valor aos clientes. }\end{array}$ \\
\hline Atividades-Chave & $\begin{array}{l}\text { Conjunto de processos executados pelas empresas para oferecer e entregar os produtos e/ou } \\
\text { serviços previstos. }\end{array}$ \\
\hline Recursos Principais & $\begin{array}{l}\text { Os recursos principais são os elementos utilizados pelas empresas para oferecer e entregar os } \\
\text { produtos e/ou serviços previstos. }\end{array}$ \\
\hline Parcerias Principais & $\begin{array}{l}\text { Algumas atividades são terceirizadas e alguns recursos são adquiridos fora das empresas por } \\
\text { meio de parcerias. }\end{array}$ \\
\hline Estrutura de Custos & Os diferentes elementos do modelo de negócio resultam na estrutura de custos da empresa. \\
\hline Fontes de Receitas & As fontes de receitas resultam de propostas de valor oferecidas com sucesso aos clientes. \\
\hline Avaliação e re(adequção) & $\begin{array}{l}\text { A exploração de uma nova tecnologia ou de um processo de inovação exige uma avaliação e } \\
\text { readequação dos modelos de negócio e dos produtos ou serviços ofertados. }\end{array}$ \\
\hline $\begin{array}{l}\text { Utilização de inovações secundárias } \\
\text { por economias emergentes }\end{array}$ & $\begin{array}{l}\text { Empresas de economias emergentes podem introduzir tecnologias e inovações emergentes, } \\
\text { provenientes de economias mais avançadas, por meio de inovações secundárias, nos modelos } \\
\text { de negócios. }\end{array}$ \\
\hline Riscos & $\begin{array}{l}\text { A perturbação das inovações disruptivas nos modelos de negócios varia, a curto e longo prazo, } \\
\text { quando orientada pela tecnologia ou quando orientada pelo mercado. }\end{array}$ \\
\hline Novos mercados & $\begin{array}{l}\text { A exploração de tecnologias e inovações emergentes dentro dos modelos de negócios } \\
\text { disruptivos proporcionam a oferta de produtos e serviços que atendam novos mercados, } \\
\text { possibilitando a obtenção de vantagem competitiva e a falha das empresas até então } \\
\text { dominantes. }\end{array}$ \\
\hline $\begin{array}{l}\text { Produtos e serviços com maior } \\
\text { simplicidade, conveniência, } \\
\text { acessibilidade e menor custo }\end{array}$ & $\begin{array}{l}\text { Tecnologias e inovações disruptivas, em sua essência, trazem uma proposta de valor muito } \\
\text { diferente para o mercado, bem como proporcionam produtos e serviços com maior simplicidade, } \\
\text { conveniência, acessibilidade e menor custo. }\end{array}$ \\
\hline Novas formas de criação de valor & $\begin{array}{l}\text { Grande preocupação e atenção dos modelos de negócios disruptivos com o seu segmento de } \\
\text { mercado selecionado, buscando novas formas de criação de valor que sensibilizem os } \\
\text { consumidores, ao invés da pura entrega de um novo produto ou serviço. }\end{array}$ \\
\hline $\begin{array}{l}\text { Ameaças aos modelos tradicionais e } \\
\text { estabilizados }\end{array}$ & $\begin{array}{l}\text { Novos modelos de negócios no mercado representam ameaças diretas e severas para a } \\
\text { manutenção dos modelos tradicionais e estabilizados. }\end{array}$ \\
\hline Comportamento empreendedor & $\begin{array}{l}\text { Possuir um comportamento empreendedor, com o propósito de analisar o mercado, bem como } \\
\text { o negócio, buscando novas formas de entregar valor ao consumidor, é fundamental para os } \\
\text { gestores, a fim de aproveitar as oportunidades e fugir das ameaças que vêm com os novos } \\
\text { modelos de negócios. }\end{array}$ \\
\hline Padrões de modelos de negócios & $\begin{array}{l}\text { Padrões de modelos de negócios podem ser utilizados para a interpretação do ambiente e para } \\
\text { a antecipação sobre a forma de se fazer o negócio pretendido, por intermédio do conhecimento } \\
\text { de elementos relacionados aos modelos de negócios disruptivos, os quais podem revelar } \\
\text { informações valiosas sobre esses aspectos. }\end{array}$ \\
\hline
\end{tabular}




\section{NOTAS}

\section{AGRADECIMENTOS}

Agradecemos a CAPES, ao CNPq, ao PPGCont/UFRGS e ao PPGA/UFRGS pelo apoio na realização do artigo, bem como à RCC pelo trabalho na divulgação das pesquisas na área contábil.

\section{CONTRIBUIÇÃO DE AUTORIA}

Concepção e elaboração do manuscrito: G. S. Schiavi, A. Behr

Coleta de dados: G. S. Schiavi

Análise de dados: G. S. Schiavi, A. Behr

Discussão dos resultados: G. S. Schiavi, A. Behr, G. R. Duarte

Redação e aprovação: G. S. Schiavi, A. Behr, G. R. Duarte

\section{CONJUNTO DE DADOS DE PESQUISA}

O conjunto de dados que dá suporte aos resultados deste estudo não está disponível publicamente.

\section{FINANCIAMENTO}

Pesquisa realizada com apoio do CNPq (424337/2018-5), de bolsa CAPES e auxílio para tradução do PPGA/UFRGS. Em conformidade com a Portaria $n^{\circ} 206$, de 4 de setembro de 2018, "o presente trabalho foi realizado com apoio da Coordenação de Aperfeiçoamento de Pessoal de Nível Superior - Brasil (CAPES) Código de Financiamento 001".

\section{CONSENTIMENTO DE USO DE IMAGEM}

Não se aplica.

\section{APROVAC̄̃̃O DE COMITÊ DE ÉTICA EM PESQUISA}

Não se aplica.

\section{CONFLITO DE INTERESSES}

Não se aplica.

\section{LICENÇA DE USO}

Os Direitos Autorais para artigos publicados neste periódico são do autor, com direitos de primeira publicação para a Revista. Em virtude de aparecerem nesta Revista de acesso público, os artigos são de uso gratuito, com atribuições próprias, em aplicações educacionais, de exercício profissional e para gestão pública. A Revista adotou a licença Creative Commons Atribuição 4.0 Internacional - CC BY NC ND. Esta licença permite acessar, baixar (download), copiar, imprimir, compartilhar, reutilizar e distribuir os artigos desde que com a citação da fonte, atribuindo os devidos créditos de autoria. Nesses casos, nenhuma permissão é necessária por parte dos autores ou dos editores. Autores têm autorização para assumir contratos adicionais separadamente, para distribuição não-exclusiva da versão do trabalho publicada nesta revista (ex.: publicar em repositório institucional ou um capítulo de livro).

\section{PUBLISHER}

Universidade Federal de Santa Catarina. Curso de Ciências Contábeis e Programa de Pós-graduação em Contabilidade. Publicação no Portal de Periódicos UFSC. As ideias expressadas neste artigo são de responsabilidade de seus autores, não representando, necessariamente, a opinião dos editores ou da universidade.

\section{EDITORES}

Carlos Eduardo Facin Lavarda e Suliani Rover

\section{HISTÓRICO}

Recebido em: 19/10/2020 - Revisado por pares em: 11/02/2021 - Reformulado em: 13/03/2021 Recomendado para publicação em: 07/05/2021 - Publicado em: 30/06/2021 